\title{
Summarization of Airport Runway Lights Cleaning Methods
}

\author{
Wei-Wei HU, Xiao-Hong GE* and Wei-Rong YE \\ Xiamen University of Technology, China, 361024 \\ 1614220356@qq.com, 348690962@qq.com, 12894779@qq.com \\ *Corresponding author: Xiao-Hong GE
}

\begin{abstract}
Keywords: Cause of dirt, Cleaning method, Discussion of effect
\end{abstract}
\begin{abstract}
The dirt on the lens surface of runway lights makes the projective light darker, affecting the aircraft's taking and landing, so it needs to clean runway lights regularly. It analyzed the cleaning efficiency, cleaning effects, environmental performance and operational safety performance of several cleaning methods, including manual cleaning, dry ice blasting, high pressure water jet, steam jet cleaning and dry powder blasting. Manual cleaning is inefficient and may be harmful to the environment. The cleaning effect of high pressure water jet, steam jet cleaning and dry ice blasting on tire rubber layer is not ideal, while dry powder blasting can wash out different kinds of dirt effectively.
\end{abstract}

\section{Preface}

The airport runway lights are used to guide the takeoff and landing of the aircraft, and also play a role when taxiing, especially at night or low visibility, runway lights playing an irreplaceable role. Friction between rubber of aircraft tire treads with ground may result in high-temperature,and the temperature can be as high as 400-500 degrees. High temperature makes the tread rubber melt, thereby bonded to the lens surface of runway lights. The mixture of oil and gas emission from aircraft, together with dust in the air attaché to the lens surface of runway lights will become dirt after a long time, resulting in projection light weakened, affecting the takeoff and landing, there is a great security risk, so it is necessary to clean the airport runway lights regularly.

The main cleaning methods of airport runway lights as following at present: manual cleaning, dry ice blasting, high pressure water jet, steam jet cleaning and dry powder blasting.

\section{Manual Cleaning}

Manual cleaning means that the cleaning workers applies the detergent to the brush or cleaning cloth, and then make mechanical friction with the surface of the lens in order to clean the dirt. The mechanism of this method is mechanical scratches and the corrosion of detergents on dirt. It can not accurately identify the interface between dirt and lens with mechanical scratches method, which may damage the surface of the lens. The acid and alkali chemical substances in detergent will cause pollution to the environment. The efficiency of manual cleaning is not high, and it takes about 5 minutes for each light to be cleaned. As of February 2017, there are 218 civil aviation airports in China, so manual cleaning can not meet the cleaning demand. As the shape of the runway is irregular, some of the dead corner can not be cleaned, therefor the cleaning process is not complete. At present manual cleaning is a common method for cleaning the runway lights in China.

\section{Dry Ice Blasting}

While the dry ice particles sprayed on the surface of the lens with high pressure air, the dirt will remove from the surface at different shrinkage rate between dirt and the lens. A brittle explosion occurs when dry ice particles reach the dirt surface at $-78^{\circ} \mathrm{C}$ that the dry ice particles instantly vaporize and expand 800 times, resulting in a strong peel force, and the dirt will quickly and completely removed from the surface with the force. As dry ice vaporizes, there is no secondary pollution except the dirt removed from the surface in the cleaning process [1-2]. CO2 is a non-toxic substance that meets the safety requirements of the US Department of Agriculture (USDA), the Food and Drug 
Administration (FDA), and the Environmental Protection Agency (EPA), so ice powder blasting is an environmentally friendly cleaning method.

As with other compressed air systems, dry ice blasting produces 80-110 dB of noise. Due to more than $100 \mathrm{~dB}$ of noise will have physiological side effects, it is necessary to wear ear protection equipment to eliminate or reduce the noise. Not only to prevent noise, but also high-speed and low temperature dry ice rebound, so it is need to wear all the protective equipment, including: durable gloves, full face mask and long sleeves[3]. The dry ice blasting system requires dry ice cleaning machine, dry ice making equipment, dry ice storage transport device which keep the temperature of dry ice under $-78^{\circ} \mathrm{C}$, so it costs high. It takes 30 seconds to clean a light, cost about $2 \mathrm{RMB}$. The overall cost is still high and only applies to large airports.

At present, there is no airport to use dry ice blasting method to clean runway lights in China. The dry ice blasting equipment designed specifically for the airport runway light by the Tokyo Sanki Engineering Co., Ltd has been used in Central Japan International Airport from 2005. With the import fee, the price of the equipment is about 2.3 million RMB.

\section{High Pressure Water Jet}

The dirt will remove from the surface with the impact and shear force which caused by the high-speed water, while the rubber still remained because there is no enough force. As the medium is water, the cleaning process does not produce secondary pollution. You can clean off the stains at the dead corner of the lamp because the water is very fluid. It takes 40 seconds to clean a light, while the cost is very low. The water left after cleaning will form ice layer if not wiped in time in the cold areas, which affecting the brightness of the runway lights, affecting the flight of the aircraft[4].

\section{Steam Jet Cleaning}

The high temperature steam dissolves the surface of the transparent mirror and vaporizes it to make the surface clean. Steam can effectively cut through any small holes and cracks peel off and remove stains and residues, which is ideal for cleaning irregularly shaped runway lights. The cleaning medium used for steam jet cleaning is water vapor, and the cleaning process does not form secondary pollution, so it is a clean cleaning method. Steam jet cleaning is effective in cleaning the oil and dust on the surface of lens, but it is not ideal for cleaning the tire rubber layer. It takes 40 seconds to clean a light ,the cleaning efficiency is high.

The runway light transmitting mirror is made of toughened glass and has the characteristics of high temperature resistance, so the high temperature steam does not affect the normal use of the light. The water consumption of Steam jet cleaning is small, just $5 \sim 10 \mathrm{~kg} / \mathrm{h}$, less than $5 \%$ of water jet cleaning. The steam temperature at the nozzle can be as high as more than 100 degrees Celsius, so it can work as usual and will not freeze at minus 30-40 degrees.

\section{Dry Powder Blasting}

The dry powder blasting is based on compressed air as the driving force to spray the powder onto the surface, removing the dirt on the surface of the lens with the impact and grinding of dry powder. The cleaning ability of dry powder blasting is very strong, and it can effectively clean all kinds of dirt on the surface of lens. Choosing soft powder can effectively protect the surface of lens from abrasion. It is easy to form dust pollution, when the dry powder impact and grind the lens surface, so it is necessary to use dust collector to recycle the dust, and you can guide water or water vapor into the nozzle to control the diffusion of dust [5-6]. The dry powder blasting also produce high decibel noise, so ear protection equipment is needed too in the process of long-term operation. The efficiency of dry powder blasting is very high, and it just takes 15 seconds to clean a light. The cost of cleaning a lamp is $0.5 \mathrm{RMB}$. The size of the dry powder is micron, and the particle speed can reach several hundred meters per second [7], so that it can reach a small gap, which can effectively clean the dirt at the dead corner.

There is no domestic dry powder blasting machine manufacturer for runway light cleaning in China and only a few aircraft airports have used imported machines for cleaning. A dry powder blasting equipment produced by Dutch company has been used in the London Heathrow International Airport. 


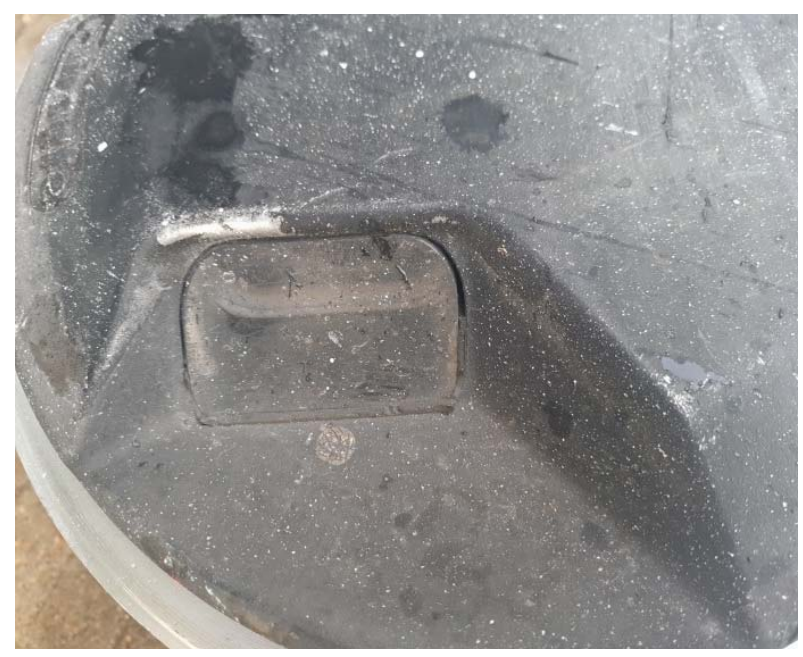

Fig. 1 Before dry powder blasting

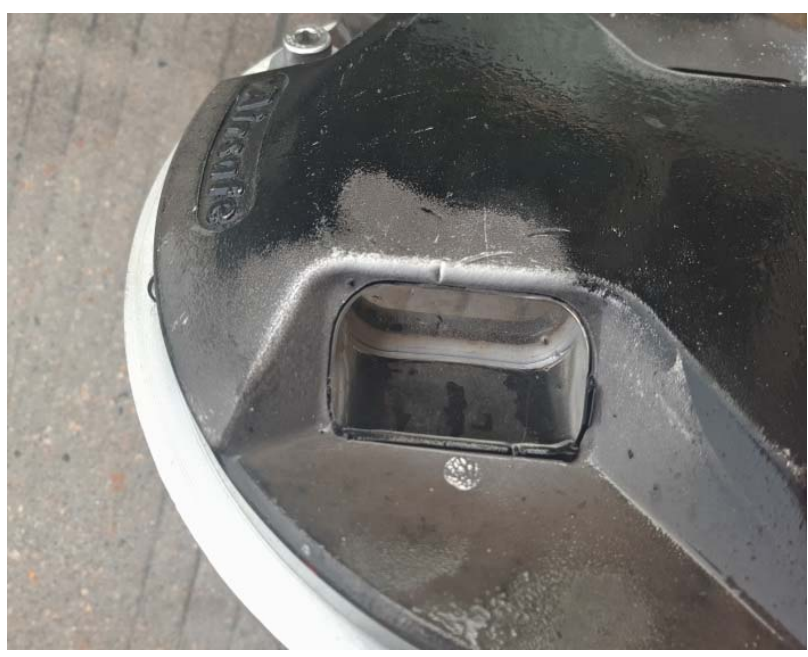

Fig. 2 After dry powder blasting

\section{Comparison of Methods}

Cleaning Efficiency

Table 1 cleaning time (unit: seconds)

\begin{tabular}{|c|c|c|c|c|c|}
\hline Cleaning method & $\begin{array}{c}\text { Manual } \\
\text { cleaning }\end{array}$ & $\begin{array}{c}\text { Dry ice } \\
\text { blasting }\end{array}$ & $\begin{array}{c}\text { High pressure } \\
\text { water jet }\end{array}$ & $\begin{array}{c}\text { Steam jet } \\
\text { cleaning }\end{array}$ & $\begin{array}{c}\text { Dry powder } \\
\text { blasting }\end{array}$ \\
\hline Cleaning time & 300 & 30 & 40 & 30 & 15 \\
\hline
\end{tabular}

The cleaning time can be seen from table 1 that manual cleaning is the longest about $300 \mathrm{~s}$, and the dry powder blasting is the shortest about $15 \mathrm{~s}$, and other methods have little difference about $30 \mathrm{~s}$

\section{Cleaning Effect}

Table 2 cleaning objects

\begin{tabular}{|c|c|c|c|c|c|}
\hline $\begin{array}{c}\text { Cleaning method } \\
\text { type of dirt }\end{array}$ & $\begin{array}{c}\text { Manual } \\
\text { cleaning }\end{array}$ & $\begin{array}{c}\text { Dry ice } \\
\text { blasting }\end{array}$ & $\begin{array}{c}\text { High pressure } \\
\text { water jet }\end{array}$ & $\begin{array}{c}\text { Steam jet } \\
\text { cleaning }\end{array}$ & $\begin{array}{c}\text { Dry powder } \\
\text { blasting }\end{array}$ \\
\hline Dust & $\begin{array}{c}\text { very } \\
\text { effective }\end{array}$ & $\begin{array}{c}\text { very } \\
\text { effective }\end{array}$ & very effective & very effective & very effective \\
\hline Rubber layer & $\begin{array}{c}\text { very } \\
\text { effective }\end{array}$ & $\begin{array}{c}\text { general } \\
\text { effect }\end{array}$ & general effect & general effect & very effective \\
\hline
\end{tabular}

The cleaning result is different because of different cleaning mechanism. Mechanical scraping by manual can clean different types of dirt. Dry ice blasting using the principle of low temperature stripping can effectively clean off the dust attachments, due to the dry ice gasifying makes the impact of the smaller force, so the cleaning effect for tire rubber layer is not ideal. Dry powder blasting can remove different types of dirt with the high velocity force of dry powder. Steam jet cleaning produces high temperature vapors that dissolve and remove dust particles, but can not remove high temperature resistant rubber. The impact of high pressure washing can remove dust, and can not remove the rubber layer. 


\section{Environmental Performance}

The cleaning chemistry detergent used by manual cleaning will cause harm to the environment. The dust produced by dry powder blasting will affect the surrounding environment. Dry ice blasting, Steam jet cleaning and high pressure water jet are clean cleaning methods, which will not produce secondary pollution to the environment.

\section{Cleaning Range}

The manual cleaning has some limitations, and it can not clean the dirt at the dead corner, while dry ice blasting, dry powder blasting, high pressure water jet and steam jet cleaning can be washed to each part.

\section{Operational Safety}

Dry ice blasting and dry powder blasting will produce noise during the cleaning process, and a long time operation will cause noise damage to the construction workers, so we need to strengthen the protection measures. We need to wear protective gloves to prevent low temperature dry ice rebound burns in dry ice blasting process. It needs to wear protective equipment before work because dust will form during dry powder blasting. The works should not be too close to the equipment in steam jet cleaning process because the temperature at the nozzle will above $100^{\circ} \mathrm{C}$ and it is easy to cause burns.

\section{Conclusion}

The efficiency of manual cleaning is very low, so it does not apply to the cleaning of large airports. And it will have secondary pollution to the environment with chemical cleaning agent. High pressure water jet and dry ice blasting are efficient, clean cleaning methods. Steam jet cleaning is an efficient, energy-saving and clean method. But the cleaning effect of the tire rubber layer is usually not satisfactory, so they are not suitable for the cleaning of the runway light. Dry powder blasting is an efficient method that can clean out different types of dirt, but the cleaning process will produce dust, if you can inhibit the dust or dust recycled, it will be a better cleaning method.

\section{Reference}

[1] ZUO Hua, Summarization of Dry Ice Purge Technology, J. Low Temperature and Specialty Gases. 2005(2).12-14

[2] LV Ping, Latest Progress in Cleaning/Polishing of Delicate Surfaces by $\mathrm{C}_{2}$ Snow Jet Spraying, J. Chinese Journal of Vacuum Science and Technology. 2016(8).955-961

[3] Zheng Li, Li Meng-Jia, Cleaning principle of dry ice cleaning machine and using cautions, J. Cleaning World.2015(2).15-18

[4] Sun Guang-Qi, Research of Decontamination Experiment of runway light and Decontamination Equipment Based On Bonding Theory, D. Cheng Du: Southwest Jiao tong University. 2009

[5] Zhao Lin-Juan, Comparisons between Cleaning Methods for Stone Relics, J. China Cultural Heritage Scientific Research. 2014(3).85-87+73

[6] Zhou Wei-Qiang, The Application of Micro-particles Blast to the cleaning of Contaminants on Stone Relics, J. Wu Han. China University of Geosciences. 2015.52-53

[7] Andreas Momber, Blast Cleaning Technology. Springer-Verlag Berlin Heidelberg.2008 